\title{
Grain yield stability of promising proso millet (Panicum miliaceum L.) genotypes for hilly region of Nepal
}

\author{
Manoj Kandel (D) 1*, Narayan Bahadur Dhami (D) 1, Tirtha Raj Rijal (D)2, Jiban Shrestha (D)3 \\ ${ }^{1}$ Nepal Agricultural Research Council, Hill Crops Research Program, Baiteshwor-4, Kabre, Dolakha, Nepal \\ ${ }^{2}$ Nepal Agricultural Research Council, Agricultural Research Station, Bijayanagar, Jumla, Nepal \\ ${ }^{3}$ Nepal Agricultural Research Council, Agriculture Botany Division, Khumaltar, Lalitpur, Nepal
}

\begin{abstract}
Identification of genotypes with a high potential for yield and stability across environments is an essential task in plant breeding. The experiments were conducted in three consecutive years viz 2017, 2018 and 2019 during spring seasons across two locations viz Dolakha; and Jumla using 13 proso millet genotypes in Nepal. Proso millet genotypes were evaluated in randomized complete block design with three replications. The objectives of this study were to analyze yield stability and adaptability of proso millets genotypes and to evaluate the discrimination and representativeness of locations by genotype and genotype by environment interaction (GGE) biplot method. The significant genotypes and genotypes and their interaction $(\mathrm{P}<0.05)$ were observed for day to maturity, plant height and grain yield which indicated the presence of difference among the genotypes. The combined analysis over environments showed that the average values of days to maturity was 118 days, plant height of $112 \mathrm{~cm}$ and grain yield of $0.429 \mathrm{t} / \mathrm{ha}$. The genotypes CO4656 had mean yield $0.495 \mathrm{t} / \mathrm{ha}$ which was higher than the overall mean $(0.429 \mathrm{t} / \mathrm{ha})$, parameter of response $(b)=1.16$ and parameter of stability $\left(S^{2} \mathrm{di}\right)=0.05$. This genotypes could be represented as stable and widely adapted across tested environments. The genotype CO3149 was specifically adapted to favourable environment of Jumla because its regression coefficient was significantly more than unity $(b=1.25)$ mean yield is higher $(0.478 \mathrm{t} / \mathrm{ha})$ than the average $(0.429 \mathrm{t} / \mathrm{ha})$ and $\mathrm{S}^{2}$ di was nearly zero $(0.101)$. Similarly genotype HUMLA-312 was specifically adapted to Dolakha environment because its regression coefficient was significantly more than unity $(\mathrm{b}=1.14)$, mean yield was higher $(0.451 \mathrm{t} / \mathrm{ha})$ than the average $(0.429 \mathrm{t} / \mathrm{ha})$ and $\mathrm{S}^{2} \mathrm{~d}$ was nearly zero $(0.140)$. GGE biplot showed genotype CO4656 was stable genotype under tested environments.
\end{abstract}

\section{ARTICLE HISTORY}

Received: 23 March 2020

Accepted: 15 June 2020

\section{KEYWORDS}

Prosomillet (Panicum miliaacum L) $\mathrm{G} \times \mathrm{E}$ interaction

GGE biplot

Yield Parameters

\section{* CORRESPONDING}

manojkandel24@gmail.com

\section{Introduction}

Proso millet (Panicum miliaacum L.) is one of the cultivated cereals and extensively cultivated in India, Nepal, Sri Lanka, Pakistan, Russia, Ukraine, the Middle East, Turkey and Romania. It is grown both in the tropics and subtropics and even at an altitude of 2700 feet (Hussain Sahib, 1997). It is hardy in nature and generally grow well on marginal lands having scarcity of irrigation as rain-fed crops (Dai et al., 2011). Because of high tolerance to heat and drought, this crop is preferred for extreme soil and climatic conditions (Reddy et al., 2007).

In Nepal, proso millet (Chino) is the second most important crop for food security among a group of millets that have a wide range of culinary uses (Ghimire et al., 2018). In the Nepalese mountains, this crop is considered a traditional and nutritionally dense crop, but its cultivation and use is shrinking fast due to labor demand, land abandonment, change in food culture and lack of research and policy support (Ghimire et al., 2018). Proso millet is one of the oldest cereal grains cultivated in the north-western part of Nepal.

Not much study and research has been done on the neglected crops, especially on foxtail millets. Identification and release of promising variety of millet the most promising and deliverable technology for increasing productivity through its utilization in crop improvement programs. (Kandel et al., 2019) and characterize the performance of local proso millet landraces over the different environments and location is necessary for plant breeder in selection and utilization in crop breeding programs.

It is important to show the relationship between genotypes and environments for selected traits graphically by use of a genotype by genotype by environment (GGE) biplot that allows visual assessment of genotype by environment interaction (GEI) pattern of multi-locational or multi-environment data (Yan et al., 2000; Yan and Hunt, 2001). 
GGE biplot model has been considered as high effective method to identify genotype difference and evaluation test environment (Ding et al., 2007). Increasingly, crop breeders have used GGE biplot widely for evaluating mean performance, stability of cultivars (Kang et al., 2006) and discrimination of test sites (Dimitrios et al., 2008). The model proposed by Eberhart and Russell (1966) has been widely employed in the last several decades mostly due to the classification of variation in genotype performance into predictable (regression) and unpredictable (deviation from regression) components. Hypothetically, Eberhart and Russell's method evaluates both yield (regression) and stability (deviation from regression), with regression being predictable and controlled to a certain extent through the selection of genotypes for specific locations. In this model, a regression coefficient greater than 1.0 indicates superior performance compared to the overall average of all genotypes (Durovic et al., 2014).

In this study, we have provided yield data of proso millet from hilly regional test of Nepal from 2017 to 2019. The objective of this study was to determine the most stable proso millet genotypes evaluating yields using some stability indexes with GGE biplot model.

\section{Materials and methods}

\subsection{Experimental site and planting materials}

The experiments were conducted at two different locations namely Dolakha and Jumla in 2017, 2018 and 2019.The research field in Jumla is located at high hill region and thus is characterized by cool temperate. The geographic coordinates for research field in Jumla are $29^{\circ} 16^{\prime} 28^{\prime \prime} \mathrm{N}$, $82^{\circ} 11^{\prime} 01^{\prime \prime} \mathrm{E}$ and 2290 masl. Soil of the research filed at Jumla was moderately deep to very deep and moderately to poor drained. Surface soil and sub-surface soils are dominantly coarse textured (Sandy loam) and are acidic to moderately alkaline in reaction.

The nitrogen content of the soil is generally very low to medium while available phosphorous is high to very high and available potassium is medium to high. The organic carbon content of farm soil is low to high (Ghimire and Mandal, 2019).

The research field in Kabre is located at mid hill region and thus is characterized by cool temperate. The geographic coordinates for research field are $86^{\circ} 09^{\prime} \mathrm{E}$ longitude, $27^{\circ} 38^{\prime} \mathrm{N}$ latitude and $1740 \mathrm{~m}$ altitude. The soil of research filed at Kabre was Sandy loam soil with $\mathrm{pH}$ from 4.5 to 6.2. i.e. slightly acidic (NARC, 2018). The climatic data during the experiments was given in Table 1.

Thirteen proso millet genotypes viz CO4651, CO4645, CO4654, CO4656, CO3149, Humla-237, Humla-239, Humla-312, Humla-383, Humla-488, Humla-530, Humla653 and Humla-725 were received from Hill Crops Research Program, Dolakha, Nepal for these experiments. The source of these proso millet millet genotypes was Nepal Agricultural Research Council, Hill Crops Research Program, Dolakha, Nepal. The origin of these genotypes was Nepal.

\subsection{Experimental design, field layout and cultural practices}

The research plot was laid out in Randomized Complete Block Design (RCBD) with 13 proso millet genotypes (accessions) as treatments and three replications. The unit plot size was $4 \mathrm{~m}^{2}$ and had 16 rows of crop sown at a distance of $25 \mathrm{~cm}$ between the rows. Inter block spacing of $1 \mathrm{~m}$ and inter plot spacing of $50 \mathrm{~cm}$ was maintained.

The seeds were sown continuous at about $2.5-3.0 \mathrm{~cm}$ deep on rows with inter row spacing of $25 \mathrm{~cm}$. Fertilizer application was done at the rate of 50:30:20 kg N:P:K per ha (HCRP, 2019). Half dose of $\mathrm{N}$ and full doses of $\mathrm{P}$ and $\mathrm{K}$ were applied as basal dose and remaining half of $\mathrm{N}$ was applied as a side dressing at the time of the tillering growth stage. The plots were kept free of weeds manually. The panicles in each plot were harvested separately by cutting from the peduncle base and placed in paper envelops.

\subsection{Data collection}

Data on grain yield and yield attributing traits were recorded according to protocol adapted by HCRP (2019). The data of day to maturity was recorded on the plot basis when $80 \%$ of plant was mature. The plant height was recorded from base of plant to base of panicle.

\subsection{Statistical analysis}

The significant $\mathrm{G} \times \mathrm{E}$ were used for stability analysis of Eberhart and Russell model (1966). A genotype with unit regression coefficient $(\mathrm{bi}=1)$ and deviation not significantly different from zero $\left(\mathrm{Sd}^{2} \mathrm{i}=0\right)$ was taken to be a stable genotype with unit response. Analysis of variance (ANOVA) was carried out on the data to assess the genotypic effects and mean comparisons among treatment means were estimated by the least significant difference (LSD) test at 5\% levels of significance (Gomez and Gomez, 1984; Shrestha, 2019). The analysis of variance was performed using RCBD design to derive variance components derived using the software packages META-R developed by CIMMYT, Mexico. The stability analysis was done using GEAR software Version 4.1 (Pacheco et al., 2015). Genstat 3.2 was used for ANOVA analysis.

\section{Results and discussion}

\subsection{Genotype $x$ environment effects}

The genotypes were significant for grain yield, plant height and days to maturity (Table 3, Table 4 and Table 5). The genotype $\mathrm{x}$ environment interaction was highly significant for grain yield, days to maturity and plant height (Table 5). The soil and climatic factor determined the grain yield of crop under study condition. All genotypes used on experiment was local collection and local germplasm so there was large variation in different traits under study condition which ultimately showed high coefficient of variation value. Adhikari et al. (2018) who reported differences among millet varieties for grain yield. The analysis of variance showed that grain yield was significant variation. Whereas genotypes into locations were found significant under study condition.

The higher coefficient of variation was observed for grain yield. This was mainly due to variation of climate and soil of the experimental fields.

\subsection{Stability analysis}

Genotypes with high mean, bi>1 with non-significant $\delta^{2}$ di are considered as below average in stability. 
Table 1. The climatic data during the experiments in Jumla and Dolakha in 2017, 2018 and 2019.

\begin{tabular}{|c|c|c|c|c|c|c|c|}
\hline \multirow[b]{2}{*}{ Year } & \multirow[b]{2}{*}{ Months } & \multicolumn{3}{|c|}{ Dolakha } & \multicolumn{3}{|c|}{ Jumla } \\
\hline & & $\begin{array}{l}\text { Max. Temp } \\
\left({ }^{\circ} \mathrm{C}\right)\end{array}$ & $\begin{array}{l}\text { Min. Temp } \\
\left({ }^{0} \mathrm{C}\right)\end{array}$ & $\begin{array}{l}\text { Total Rainfall } \\
\text { (mm) }\end{array}$ & $\begin{array}{l}\text { Max. Temp } \\
\left({ }^{\circ} \mathrm{C}\right)\end{array}$ & $\begin{array}{l}\text { Min. Temp } \\
\left({ }^{\circ} \mathrm{C}\right)\end{array}$ & $\begin{array}{c}\text { Total Rainfall } \\
(\mathrm{mm})\end{array}$ \\
\hline \multirow{5}{*}{2017} & April & 25 & 15 & 99 & 24.34 & 7.9 & 42.8 \\
\hline & May & 25 & 16 & 289 & 25.42 & 15.48 & 180.1 \\
\hline & June & 26 & 19 & 585 & 25.66 & 15.48 & 180.1 \\
\hline & July & 25 & 19 & 497 & 24.1 & 16.4 & 280.1 \\
\hline & August & 27 & 18 & 478.1 & 24.6 & 16.2 & 123.8 \\
\hline \multirow{5}{*}{2018} & April & 26.5 & 12.5 & 73.6 & 22.1 & 6.1 & 40.3 \\
\hline & May & 28.5 & 13.3 & 180.3 & 25.2 & 8.6 & 62.2 \\
\hline & June & 28.8 & 17 & 181.3 & 27.3 & 14.4 & 65 \\
\hline & July & 28 & 18.5 & 552.6 & 24.3 & 15.8 & 160.4 \\
\hline & August & 27.5 & 19 & 378.4 & 24.1 & 16.3 & 225.4 \\
\hline \multirow{5}{*}{2019} & April & 33 & 15 & 70.1 & 22.4 & 6.8 & 70.5 \\
\hline & May & 28 & 18 & 190.1 & 24.2 & 7.6 & 31.5 \\
\hline & June & 28 & 23 & 199 & 26.2 & 12.7 & 65.1 \\
\hline & July & 26 & 20 & 510 & 23.88 & 16.17 & 252.6 \\
\hline & August & 26 & 19 & 366 & 25.05 & 14.72 & 102.7 \\
\hline
\end{tabular}

(Source: Horticultural Research Station (HRS), 2018, 2019, 2020; HCRP, 2018, 2019, 2020)

Table 2. Combined analysis of variance (ANOVA) for grain yield of 13 proso millet genotypes in Dolakha and Jumla environments in 2017, 2018 and 2019.

\begin{tabular}{|l|c|c|c|c|}
\hline Source of variation & d.f. & s.s. & m.s. & F value \\
\hline Genotypes (G) & 12 & 0.6597 & 0.05497 & $0.196^{*}$ \\
\hline Environments (E) & 1 & 1.01665 & 1.01665 & $0.001^{* *}$ \\
\hline GX E Interaction & 12 & 0.58806 & 0.04901 & $0.277^{*}$ \\
\hline Blocks & 4 & 2.565 & 0.6413 & $0.001^{* *}$ \\
\hline Error & 50 & 1.95993 & 0.0392 & \\
\hline Total & 77 & 6.10033 & & \\
\hline
\end{tabular}

**Significant at $1 \%$ level, *Significant at $5 \%$ level.

Table 3. Performance of proso millet genotypes in Dolakha in 2017, 2018 and 2019.

\begin{tabular}{|l|l|c|c|c|c|c|c|c|c|c|}
\hline \multirow{2}{*}{ SN } & \multirow{2}{*}{ Genotypes } & \multicolumn{3}{|c|}{2017} & \multicolumn{3}{|c|}{2018} & \multicolumn{3}{c|}{2019} \\
\cline { 3 - 12 } & & DTM & PH & GY & DTM & PH & GY & DTM & PH & GY \\
\hline 1 & Co4651 & 101 & 93 & 0.382 & 106 & 83 & 0.578 & 108 & 85 & 0.166 \\
\hline 2 & CO4645 & 104 & 102 & 0.333 & 106 & 90 & 0.638 & 109 & 94 & 0.142 \\
\hline 3 & CO4654 & 102 & 111 & 0.849 & 98 & 86 & 0.773 & 102 & 88 & 0.186 \\
\hline 4 & CO4656 & 101 & 106 & 1.104 & 102 & 94 & 0.643 & 104 & 95 & 0.205 \\
\hline 5 & CO3149 & 102 & 97 & 0.931 & 100 & 77 & 0.675 & 102 & 78 & 0.132 \\
\hline 6 & Humla-237 & 103 & 95 & 0.350 & 100 & 83 & 0.733 & 105 & 85 & 0.179 \\
\hline 7 & Humla-239 & 101 & 93 & 0.020 & 94 & 88 & 0.730 & 101 & 90 & 0.252 \\
\hline 8 & Humla-312 & 88 & 107 & 0.950 & 99 & 106 & 0.703 & 103 & 103 & 0.239 \\
\hline 9 & Humla-725 & 103 & 93 & 0.858 & 101 & 93 & 0.675 & 100 & 96 & 0.161 \\
\hline 10 & Humla-488 & 103 & 104 & 0.933 & 102 & 77 & 0.783 & 106 & 80 & 0.197 \\
\hline 11 & Humla-530 & 103 & 97 & 0.870 & 101 & 78 & 0.788 & 105 & 80 & 0.166 \\
\hline 12 & Humla-653 & 117 & 97 & 0.917 & 99 & 80 & 0.805 & 100 & 82 & 0.161 \\
\hline 13 & Humla-383 & 101 & 90 & 0.711 & 100 & 87 & 0.693 & 99 & 90 & 0.188 \\
\hline & Grand Mean & 102 & 99 & 0.291 & 100 & 86 & 0.710 & 103 & 88 & 0.183 \\
\hline & F test & $*$ & $*$ & $*$ & $*$ & $*$ & $*$ & $*$ & $*$ & $*$ \\
\hline & CV(\%) & 8.26 & 9.68 & 19.87 & 3.9 & 12.3 & 13.6 & 12.28 & 9.18 & 18.91 \\
\hline & LSD(0.05) & 18.34 & 20.84 & 0.43 & 8.5 & 23.1 & 0.20 & 6.36 & 3.19 & 0.28 \\
\hline
\end{tabular}

DTM=80\% day to maturity, PH=Plant height ( $\mathrm{cm}), G Y=$ Grain Yield (t/ha), *Significant at 0.05 probability level, LSD = Least significant difference at 0.05 level, $C V=$ Coefficient of variation. 
Table 4. Performance of proso millet genotypes in Jumla in 2017, 2018 and 2019.

\begin{tabular}{|l|l|c|c|c|c|c|c|c|c|c|}
\hline \multirow{2}{*}{ SN } & \multirow{2}{*}{ Genotypes } & \multicolumn{3}{|c|}{2017} & \multicolumn{3}{|c|}{2018} & \multicolumn{3}{|c|}{2019} \\
\cline { 3 - 12 } & & DTM & PH & GY & DTM & PH & GY & DTM & PH & GY \\
\hline 1 & CO4651 & 130 & 138 & 0.536 & 130 & 140 & 0.803 & 136 & 132 & 0.131 \\
\hline 2 & CO4645 & 129 & 134 & 0.266 & 130 & 138 & 0.167 & 136 & 143 & 0.101 \\
\hline 3 & CO4654 & 127 & 148 & 0.611 & 127 & 150 & 0.512 & 132 & 153 & 0.322 \\
\hline 4 & CO4656 & 141 & 175 & 0.433 & 144 & 169 & 0.334 & 144 & 162 & 0.694 \\
\hline 5 & CO3149 & 132 & 142 & 0.527 & 133 & 138 & 0.428 & 138 & 142 & 0.288 \\
\hline 6 & Humla-237 & 131 & 146 & 0.474 & 130 & 147 & 0.375 & 134 & 137 & 0.185 \\
\hline 7 & Humla-239 & 131 & 141 & 0.087 & 133 & 145 & 0.191 & 134 & 147 & 0.137 \\
\hline 8 & Humla-312 & 129 & 161 & 0.323 & 135 & 157 & 0.224 & 134 & 143 & 0.145 \\
\hline 9 & Humla-7253 & 130 & 155 & 0.414 & 132 & 151 & 0.315 & 133 & 152 & 0.125 \\
\hline 10 & Humla-488 & 131 & 155 & 0.277 & 136 & 153 & 0.178 & 135 & 156 & 0.284 \\
\hline 11 & Humla-530 & 121 & 150 & 0.262 & 125 & 145 & 0.163 & 131 & 146 & 0.041 \\
\hline 12 & Humla-653 & 123 & 163 & 0.114 & 125 & 160 & 0.015 & 133 & 158 & 0.108 \\
\hline 13 & Humla-383 & 132 & 125 & 0.564 & 135 & 128 & 0.465 & 137 & 129 & 0.275 \\
\hline & Grand Mean & 130 & 149 & 0.376 & 132 & 148 & 0.32 & 135 & 146 & 0.217 \\
\hline & F test & $*$ & $*$ & $*$ & $*$ & $*$ & $*$ & $*$ & $*$ & $*$ \\
\hline & CV(\%) & 3.06 & 9.4 & 28.43 & 3.9 & 8.3 & 27.6 & 2.67 & 7.25 & 26 \\
\hline & LSD(0.05) & 8.63 & 30.44 & 0.48 & 11.3 & 26.7 & 0.40 & 7.85 & 23.07 & 0.33 \\
\hline
\end{tabular}

$D T M=80 \%$ day to maturity, $P H=$ Plant height $(\mathrm{cm}), G Y=$ Grain Yield $(t / h a)$, *Significant at 0.05 probability level, $L S D=$ Least significant difference at 0.05 level, $C V=$ Coefficient of variation

Table 5. Combined performances of proso millet genotypes in Jumla and Dolakha in 2017, 2018 and 2019.

\begin{tabular}{|l|l|c|c|c|}
\hline SN & Genotype & DTM & PH & GY \\
\hline 1 & CO4651 & 118 & 112 & 0.517 \\
\hline 2 & CO4645 & 118 & 116 & 0.264 \\
\hline 3 & CO4654 & 114 & 122 & 0.494 \\
\hline 4 & CO4656 & 122 & 133 & 0.495 \\
\hline 5 & CO3149 & 118 & 112 & 0.478 \\
\hline 6 & Humla-237 & 116 & 115 & 0.381 \\
\hline 7 & Humla-239 & 115 & 117 & 0.428 \\
\hline 8 & Humla-312 & 114 & 130 & 0.451 \\
\hline 9 & Humla-725 & 117 & 123 & 0.417 \\
\hline 10 & Humla-488 & 118 & 121 & 0.447 \\
\hline 11 & Humla-530 & 113 & 116 & 0.375 \\
\hline 12 & Humla-653 & 116 & 123 & 0.346 \\
\hline 13 & Humla-383 & 117 & 107 & 0.484 \\
\hline & Grand Mean & 118 & 112 & 0.429 \\
\hline & F-test (G) & $*$ & $*$ & $*$ \\
\hline & G $\mathrm{E}$ & $*$ & $*$ & 14.99 \\
\hline & CV(\%) & 4.38 & 9.07 & 0.195 \\
\hline & LSD(0.05) & 8.49 & 14.16 & ( \\
\hline
\end{tabular}

DTM=80\% day to maturity, $P H=$ Plant height $(\mathrm{cm}), G Y=$ Grain Yield $(\mathrm{t} / \mathrm{ha}), \mathrm{G} \times \mathrm{E}=\mathrm{Genotypes}$ into environment interaction, $\mathrm{b}=$ parameter of response, *Significant at 0.05 probability level, $L S D=$ Least significant difference at 0.05 level, CV=Coefficient of variation .

Such genotypes tend to respond favorably to better environments but give poor yield in unfavorable environments. Hence, they are suitable for favorable environments (Eberhart and Russell, 1966). The genotypes namely CO4656 ( $b=1.161), C O 3149(b=1.250)$ and Humla- $383(b=1.176)$ had more than unity regression indicating the genotype's suitability towards favorable environments (Table 6). The proso millet genotype CO4656 (0.495 t/ha) were suitable for mid hill environments of Nepal. 
Table 6. Grain yield performance and stability parameters of proso millet genotypes in Jumla and Dolakha using Eberhart and Russell model in 2017, 2018 and 2019.

\begin{tabular}{|l|l|c|c|c|c|c|}
\hline \multirow{2}{*}{$\mathrm{SN}$} & \multirow{2}{*}{ Genotypes } & \multicolumn{4}{|c|}{ Stability parameters } \\
\cline { 3 - 7 } & $\mathrm{Sd}$ & $\mathrm{CV}(\%)$ & $\mathrm{bi}$ & $\mathrm{S}^{2} \mathrm{di}$ & $\mathrm{R}^{2}$ \\
\hline 1 & CO4651 & 206.23 & 23.38 & 0.610 & -0.403 & 0.693 \\
\hline 3 & CO4645 & 213.63 & 18.99 & 0.741 & -0.332 & 0.755 \\
\hline 4 & CO4654 & 207.69 & 22.04 & 0.640 & -0.360 & 0.696 \\
\hline 5 & CO4656 & 338.38 & 18.56 & 1.161 & 0.050 & 0.958 \\
\hline 6 & Humla-237 & 313.93 & 15.61 & 1.250 & 0.101 & 0.959 \\
\hline 7 & Humla-239 & 207.45 & 14.40 & 0.561 & -0.438 & 0.660 \\
\hline 8 & Humla-312 & 374.21 & 17.42 & 1.265 & 0.065 & 0.718 \\
\hline 9 & Humla-725 & 212.63 & 18.77 & 1.140 & 0.140 & 0.848 \\
\hline 10 & Humla-488 & 323.95 & 17.72 & 0.788 & -0.211 & 0.863 \\
\hline 11 & Humla-530 & 359.21 & 12.48 & 1.228 & 0.228 & 0.903 \\
\hline 12 & Humla-653 & 402.45 & 15.66 & $1.414 *$ & $0.414 *$ & 0.973 \\
\hline 13 & Humla-383 & 299.27 & 16.47 & $1.521 *$ & $0.521^{*}$ & 0.898 \\
\hline
\end{tabular}

$S d=$ Standard deviation, $C V=$ Coefficient of variation. bi $=$ regression coefficient, $R^{2}=$ coefficient of determination (Eberhart and Russell 1966). *Significant at 0.05 probability level

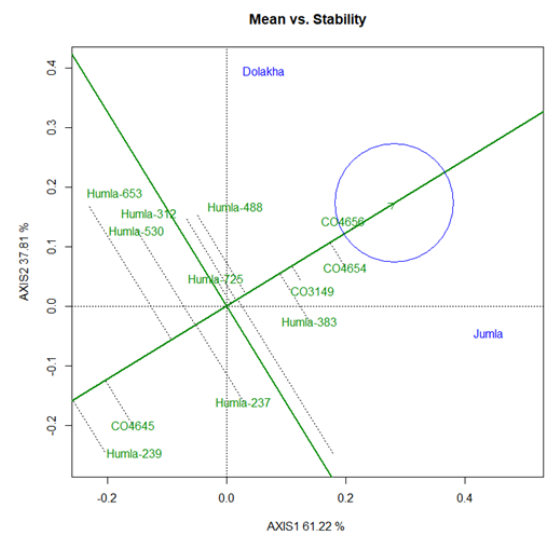

Figure 1. GGE biplot showing ranking of genotypes for mean yield and stability performance over environments

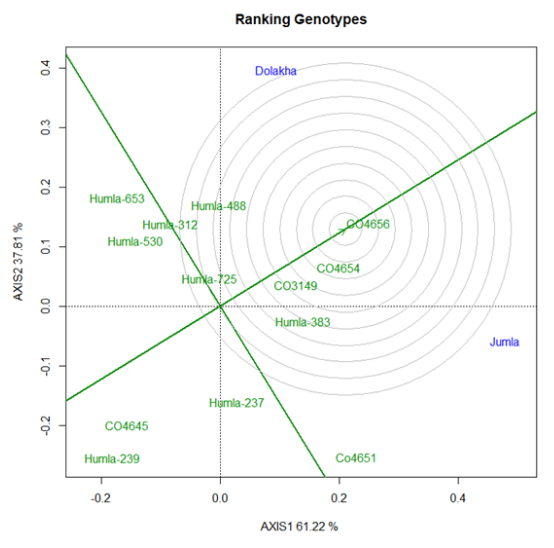

Figure 2. GGE biplot of ideal genotype and the comparison of genotypes with respect to the ideal genotype.

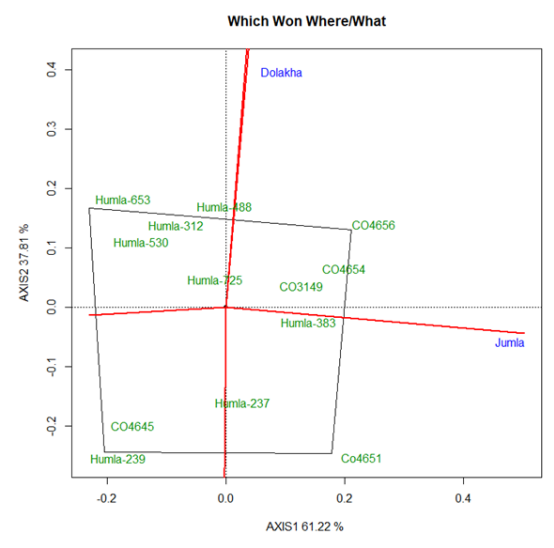

Figure 3. Mega-Environment Delineation by GGE Biplot for prosomillet productivity data $\left(\mathrm{t} \mathrm{ha}^{-1}\right)$ with 13 genotypes (G) and two environments (E) in 2017, 2018 and 2019.

\subsection{GGE biplot analysis}

Stability in the yield performance is the major concern to the breeder and influenced mostly by genotype $\mathrm{x}$ environment interaction (Zobel et al., 1988). In GGE biplot methodology, the estimation of yield and stability of genotypes (Figure 1) were done by using the average environment (tester) coordinate methods (Yan and Hunt, 2001). The line passing through the biplot origin is called the environment and is suitable in its performance. For broad selection, the ideal genotypes are those that have both high mean yield and high stability. An ideal genotype should have average environment (tester) coordinate, which is defined by the average PC1 and PC2 scores for all environments (Yan and Kang, 2003). More close to concentric circle indicates higher mean yield. Thus, genotype CO4656 was the most stable genotype. An ideal genotype gives the highest yield across tested the highest mean performance and be absolutely stable (Yan and Kang, 2003).

\subsection{Ranking of genotypes}

An ideal genotype, which is located at the center of the concentric circle is the one that has both high mean yield and high stability (Yan and Kang, 2003). Therefore, the results showed that genotype CO4656 was stable (Figure 2). Similar findings were reported in buckwheat by Kandel et al. (2019).

\subsection{Mega-environment analysis by GGE biplot}

While GGE biplot of PC1 scores explained $61.22 \%$, PC2 scores explained $37.81 \%$ of the total G+GE variation, totalizing $99.03 \%$ (Figure 3). One attractive feature of the GGE biplot is to graphically show the 'which-won-where' pattern of a genotype environment two-way data (Yan et al., 
2000), revealing mega-environments. Mega-environments on biplot consist of an irregular polygon and a set of straight lines that radiate from the biplot origin to intersect each of the polygon sides at right angles (Yan, 2011). The Figure 3 showed that the vertex genotypes of a polygon were CO4656, CO4651, Humla-239 and Humla-653. The genotypes positioned on the vertexes are the best or poorest in some or all environments because they are farthest from the origin of biplot (Yan and Kang, 2003), which were more responsive to environmental change and are considered as specially adapted genotypes. The lines red line perpendicular to the polygon separated the mega-environments.

\section{Conclusion}

In this study, GGE biplot was used to evaluate yield stability and test location representativeness in hilly regions of Nepal for proso millet genotypes. The performance and yield stability across different environments varied among Proso millet genotypes. Based on results, proso millet genotypes namely CO4656, CO3149 and Humla-383 gave higher grain yield and showed adaptability under favorable environments. The genotype namely CO4656 was identified more stable, high yielding and adaptive genotypes across the hilly environments of Nepal. Thus, this genotype was recommended for possible release for wider adaptability across Jumla and Dolakha and other areas with similar agroecology in the country. Thus, this genotype was recommended for release as variety to improve proso millet production in hilly environments of Nepal.

\section{Acknowledgement}

The authors would like to provide their thanks to technical staffs of Hill Crops Research program (HCRP), Kabre, Dolakha, and Agricultural Research Station (ARS), Bijayanagar, Jumla, Nepal for their technical support to carry out this study. The funds for this research was received from Nepal Agricultural Research Council, Nepal

\section{Authors' Contributions}

M. Kandel conducted experiments, analyzed data and wrote initial draft of manuscript. N.B. Dhami and T.R. Rijal provided planting materials, experimental fields and helped in conducting experiments in fields. J. Shrestha helped in preparing graphs and finalized the initial draft of this manuscript.

\section{Conflict of Interest}

The authors declare that they have no conflicts of interest.

\section{References}

Adhikari, B.N., Pokhrel, B.B., \& Shrestha, J. (2018). Evaluation and development of finger millet (Eleusine coracana L.) genotypes for cultivation in high hills of Nepal. Farming and Management, 3(1), 37-46

Dai, H. P., Jia, G.L., Lu, C., Wei, A. Z., Feng, B.L., \& Zhang, S. Q. (2011). Studies of synergism between root system and leaves senescence in Broomcorn millet (Panicum miliaceum L.). J Food, Agric Environ, 9 (2), 177-180.

Dimitrios, B., Christos, G., Jesus, R., \& Eva, B. (2008). Separation of cotton cultivar testing sites based on representativeness and discriminating ability using GGE biplots. Agronomy Journal, 100, 1230-1236.
Ding, M., Tier, B., \& Yan, W.K. (2007). Application of GGE biplot analysis to evaluate genotype $(\mathrm{G})$, environment $(\mathrm{E})$ and $\mathrm{G} \times \mathrm{E}$ interaction on $\mathrm{P}$. radiata: Case study. In: Australasian Forest Genetics Conference, 11-14, April 2007. The Old Woolstore, Hobart, Tasmania, Australia

Durovic, D.S., Madic, M.R., Bokan, N.R., Stevovic, V.I., Tomic, D.D., \& Tanaskovic, S.T. (2014). Stability parameters for grain yield and its component traits in maize hybrids of different FAO maturity group. Journal of Central European Agriculture, 15(4), 99-212.

Eberhart, S.A., \& Russell, W.A. (1966). Stability parameters for comparing varieties. Crop Science, 6(1), 36-40.

Gauch, H.G., \& Zobel, R.W. (1997). Identifying megaenvironments and targeting genotypes. Crop Sci., 37, 311326.

Ghimire, K.H., Joshi, B.K., Dhakal, R., \& Sthapit, B.R. (2018). Diversity in proso millet (Panicum miliaceum L.) landraces collected from Himalayan mountains of Nepal. Genet Resour Crop Evol., 65, 503-512.

Ghimire, N.H., \& Mandal, H.N. (2019). Genetic Variability, Genetic Advance, Correlation and Heritability of Cold Tolerance Lentil (Lens culinaris Medic.) Genotypes at High Hill of Nepal. Int. J. Adv. Res. Biol. Sci., 6(11), 1-10.

Gomez, K.A., \& Gomez, A. (1984). Statistical Procedure for Agricultural Research-Hand Book. John Wiley and Sons, New York.

HCRP (2018). Annual report, Hill Crops Research Program (HCRP), Kabre, Dolakha, Nepal.

HCRP (2019). Annual report, Hill Crops Research Program (HCRP), Kabre, Dolakha, Nepal.

HCRP (2020). Annual report, Hill Crops Research Program (HCRP), Kabre, Dolakha, Nepal.

HRS (2018). Annual Report of Horticultural Research Station, Rajkot, Jumla, Nepal.

HRS (2019). Annual Report of Horticultural Research Station, Rajkot, Jumla, Nepal.

HRS (2020). Annual Report of Horticultural Research Station, Rajkot, Jumla, Nepal.

Hussain, S.K. (1997). Importance of Proso millet in Indian Agriculture. In: Extended Summaries of National Seminar on Small Millets, Current Research trends and future priorities as food, feed and in processing for value addition, GKVK, Bangalore, p11-12.

Kandel, M., \& Shrestha, J. (2019). Genotype x environment interaction and stability for grain yield and yield attributing traits of buckwheat (Fagopyrum tataricum Geartn). Syrian Journal of Agricultural Research, 6(3), 466-476.

Kandel, M., Dhami, N.B., Bastola, A., Sudedi, N.R., \& Shrestha, J. (2019). Field evaluation and nutritional benefits of finger millet (Eleusine coracana (L.) Gaertn.). International Journal of Global Science Research, 6(1), 711722.

Kang, M.S., Aggarwal, V.D., \& Chirwa, R.M. (2006). Adaptability and stability of bean cultivars as determined via yieldstability statistic and GGE biplot analysis. Journal of Crop Improvement, 15, 97-120.

NARC. (2018). Annual Report (2017/18) of Nepal Agricultural Research Council (NARC), Hill Crops Research Program, Kabre, Dolakha, Nepal.

Pacheco, A., Vargas, M., Alvarado, G., Rodríguez, F., López, M., Crossa, J., \& Burgueño, J. (2015). User's Manual GEAR (Genotype by Environment Analysis with R). "GEA-R (Genotype x Environment Analysis with R for Windows) Version 4.1", hdl:11529/10203, CIMMYT Research Data 
and Software Repository Network, V16.

Reddy, V., Upadhyaya, H., \& Gowda, C. L. L. (2007). Morphological characterization of world's proso millet germplasm. Journal of SAT Agricultural Research. 3.

Shrestha, J. (2019). P-Value: A true test of significance in agricultural research. Retrieved from https://www.linkedin.com/pulse/p-value-test-significanceagricultural-research-jiban-shrestha/
Yan. W., \& Hunt, L. A. (2001). Biplot Analysis of MultiEnvironment Trial Data In. Quantitative Genetics, Genomics and Plant Breeding. Kang, M. S., (Ed.), CABI Publishing, New York. pp289-303.

Yan, W., \& Kang, M.S. (2003). GGE biplot analysis: a graphical tool for breeders, Geneticists and Agronomists. CRC Press LLC., Boca Raton, Florida, pp: 271.

Turkish Journal of Food and Agriculture Sciences is licensed under a Creative Commons Attribution-NonCommercial-NoDerivatives 4.0 International License 